\title{
Understanding a Specific Walkable Space via the Phenomenon of Chinese Street Vending: An actor- network theory analysis
}

\author{
Ziwen Sun, Simon Bell, lain Scott \\ Edinburgh School of Architecture and Landscape Architecture, \\ University of Edinburgh, UK
}

Ziwen.Sun@ed.ac.uk.

\begin{abstract}
In contemporary Chinese cities, the pervasive phenomenon of street vending often emerges in a predictable space where numerous people frequently walk or stay. Using actor-network theory as a conceptual tool, this study initially elaborates a set of physical and social processes of configuration regarding Chinese street vending in walkable spaces. The network analysis involves heterogeneous actors and multiple associations regarding two groups of people, livelihoods and demands, mobile amenities, dietary habits, urban micro-economy, and collective participation. The results illustrate additional knowledge to why walkability, and how a specific walkable space is configured in the Chinese context.
\end{abstract}

Keywords: Street vendors; Walkable spaces; Actor-network theory; Specificity

eISSN 2398-4295 @ 2018. The Authors. Published for AMER ABRA cE-Bs by e-International Publishing House, Ltd., UK. This is an open-access article under the CC BY-NC-ND license (http://creativecommons.org/licenses/bync-nd/4.0/). Peer-review under responsibility of AMER (Association of Malaysian Environment-Behaviour Researchers), ABRA (Association of Behavioural Researchers on Asians) and $c E-B s$ (Centre for EnvironmentBehaviour Studies), Faculty of Architecture, Planning \& Surveying, Universiti Teknologi MARA, Malaysia.

DOI: http://dx.doi.org/10.21834/ajbes.v3i13.156 


\subsection{Introduction}

Due to the social and physical benefits of walking are many (e.g. public health, environmental pollution, neighbourhoods' interaction, misdirected investment and shrinking cities), promoting walkability is becoming an increasingly important aim among public health researchers, urban planners and designers (Saelens, Sallis, \& Frank, 2003; Ewing \& Handy, 2009; Speck, 2013; Sun, et al., 2015; Brookfield, et al., 2017). Many studies have proved the complex correlations between built environment and walkability (e.g. land use, nearby amenities, population density, micro-climate, and street network). However, only a few studies attempt to understand the specific attributes of walkable spaces in a socio-cultural context (Saelens \& Handy, 2008; Sun \& Kong, 2015; Brookfield, et al., 2017).

In contemporary Chinese cities, street vendors regularly emerge in a predictable space where many people frequently walk or rest. As such, the ubiquitous phenomenon of street vending closely appears to have a relationship with the walkability of urban spaces. The majority of Chinese researchers focus on street vending negatively and try to solve or manage the phenomenon. This is due to street vendors being seen to contribute to "dirty, noisy and disordered" outdoor spaces (Liu, 2013; Huang, Xue, \& Li, 2014). In recent years, a few studies have started challenging this mainstream view, which stands on the neoliberalism and neo-Marxism to represent an ambiguous position, which means that treat street vendors as "a necessary conflict" making suggestions for a reframing of policy (Huang, Xue, \& Li, 2014). However, no study examines how street vendors engage with walkable urban spaces.

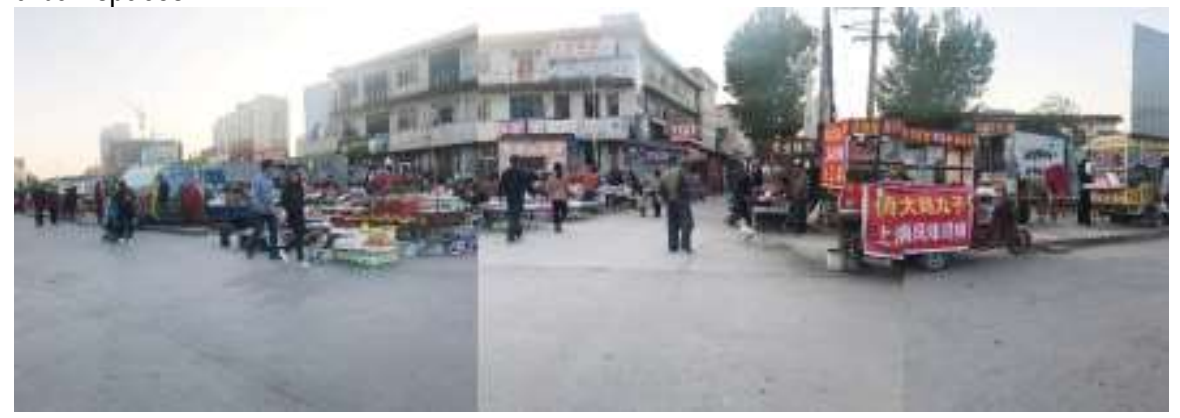

Figure 1: Various street vendors engaged with walkable spaces, Yuncheng, China (Source: Ziwen Sun)

This paper mainly uses actor-network theory (ANT) as a conceptual tool to understand the specificity of walkability in a particular space via the phenomenon of street vending. ANT not only focuses on controversy and conflict (Ramiller \& Wagner, 2009) but also offers an opportunity to explore an invisible order behind a phenomenon (Wissink, 2013). The first part discusses the use of ANT, which sets up the constructive framework and theoretical concept in relation to the phenomenon of street vending. The second part is an introduction to the controversy in respect of street vending that rejects the negative attitude as a conventional Chinese perspective. The third part discusses the material actors involved in this network of street vending, including two groups of people and mobile amenities. The following part 
explains the immaterial actors, which investigates the spontaneous socio-economic orders that emerge due to the livelihoods and demands of everyday life. The last part binds all actors and associations together to generate a complete actor-network of street vending that clarifies a paradigm of walkability.

\subsection{Literature Review}

\subsection{Actor-network theory and the phenomenon of street vending}

ANT is underpinned by a significant philosophical concept called 'the sociology of translation' (Pentland \& Feldman, 2007). It rejects differences between human and non-human actors, as well as a priori knowledge and reducible hierarchical ideas (Latour, 2005; Sheehan \& Vadjunec, 2012). ANT attempts to reveal associations between actors under the premise that such associations are unpredictable and bilateral. Vayda (1983) explains that any actornetwork approach requires being aware of all possible actors that can be placed within increasingly multiple associations considering broader contexts. Mitev (2009) notes that actors can be individuals, groups, institutions, culture and artefacts, which can be intertwined in continuously changing associations.

Castells (1996) posits a concept of 'space of flow'. He argues that physical space is a representation of society and an expression of everyday life. Social practices and spaces are naturally intertwined (Wissink, 2013). In this way, the research will attempt to understand the specific social phenomenon of street vending through a socio-spatial approach, which acknowledges the phenomenon as a positive contributor to walkable urban spaces.

ANT has a new perspective that illustrates how associations of physical and social actors emerge together regarding 'social explanations and technologies' (Latour, 2005). In this research, the two aspects can be replaced by 'everyday demands and walkable spaces'. Latour (1987) claims that translation is happening, that the process of space is running. Thus the spaces studied are constantly in a state of flux and change. Therefore, street vending should consider the process of configuration and acceptance of associations.

Actors never act alone, but act within actor-networks, through various agencies (Latour, 2005). The phenomenon of street vending cannot be simply understood as a single 'thing', but rather has to be considered as a series of associations perform, work and rework. Street vendors are understood not only as dynamic reflections of space and time but also as constitutive and performative contributors to a variety of social and environmental processes at multiple scales.

The aim of this paper is to explore why exactly street vending does emerge; which actors maintain the phenomenon. It is focusing on one particular actor-network (a set of actors and associations) of street vending to understand how and why two groups (street vendors and nearby residents) construct the specific walkable space. Namely, this study proposes a new insight to understand the meanings of specific walking behaviours via the processes of the configuration of street vending. This research involves a long terms observation of Yuncheng's street vending areas. The choice of Yuncheng arises from its common position in Chinses cities. The semi-structured interviews are used to deeply understand the 
meanings of street vending and specific walking behaviours.

\subsection{The controversy of street vending in contemporary Chinese cities}

In contrast to earlier Chinese urban policies, for instance, the exclusionary strategy towards street vendors in Guangzhou has been carried out by the National Sanitary City campaign as 'revanchism' that tries to erase the undesirable populations from public space (Huang et al., 2014). However, the resistance of street vendors, who possess an individualised, varied, adaptable and flexible activism to sustain their livelihoods, has seen the exclusionary strategy encounter implementation difficulties. Moreover, due to street vendors serving the demands of nearby residents, a desire for social harmony at a national level has impelled local government to seek alternatives in attempts to mitigate collective resistance. As such, today an ambivalent strategy exists, seeking to alleviate tension between the demands to maintain clean urban images and improve the livelihoods of the poor in Chinese urban areas (ibid.).

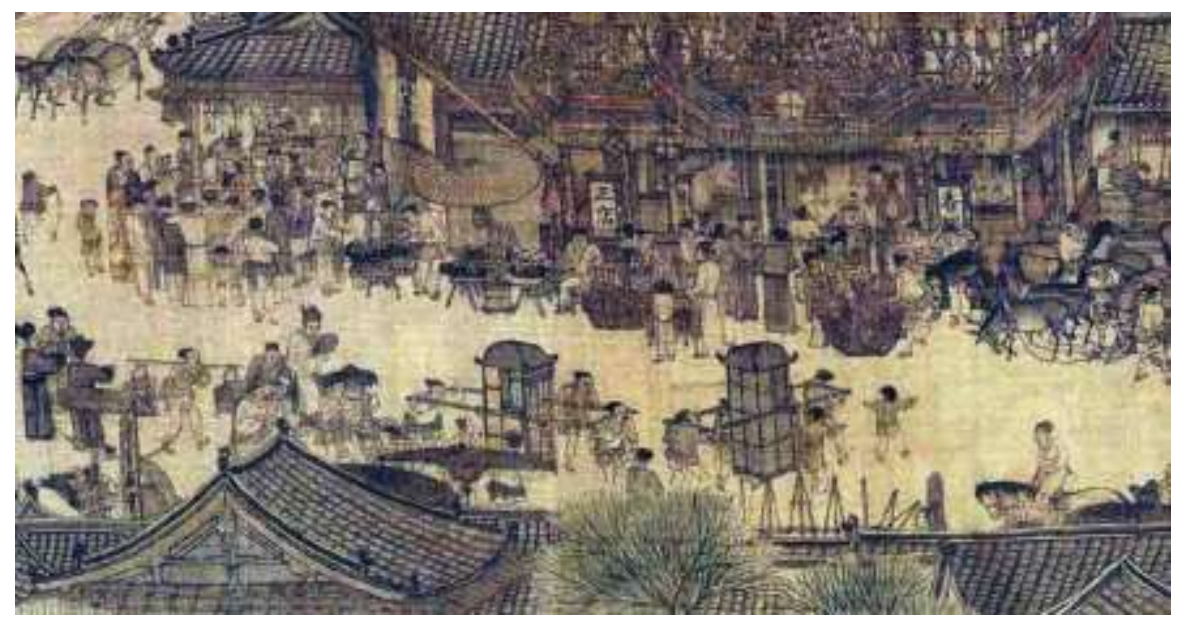

Figure 2: A part of the painting of Along the River During the Qingming Festival

(Source: Zeduan Zhang, Song dynasty, 1085-1145)

The prevalence of street vending in China emerges from ancient times. Unfortunately, as they have always been part of informal business practices and come from self-organisation, the phenomenon is impossible to trace its origin and historical record. It is not certain to what this refers, but a distinguished Chinese traditional landscape painting, named "Along the River During the Qingming Festival", captures the everyday life of ancient Chinese people, and represents the street vendors, in Bianjing (today's name Kaifeng), from the Northern Song period (almost 1000 years ago) (Murray, 1997). This is intended to indicate that the majority of actors of outdoor spaces have disappeared. However, a part of Genius Loci (Norberg-Schulz, 1980) in the painting, as the ancient liveable space, has been translated through the features of street vendors into contemporary Chinese cities.

Technologies change swiftly while humans change slowly. New technologies tend to 
hugely impact the development of cities and urban planning regarding automobiles, computers and the Internet (Le \& Etchells, 1946; Kelly, 2010). It is likely that future generations will require different urban patterns and activities. However, the time-tested and historical forms, as well as elements and phenomena, can adopt the new technologies and satisfy the elementary needs to engage people moving to cities, where people can live, play and work effectively, potentially achieving self-actualisation (Moore, 2015). In this way, the time-tested street vending might emerge in many urban places, but its precise functions, forms, time, meanings, features, properties, systems and influences have to be analysed in relation to associations in specific spaces and local contexts.

\subsection{Functions of street vending - material actors}

\subsubsection{A survival function - livelihood (the feature of a human actor)}

The behaviour of street vendors is a simple survival means for surplus labourers, particularly affected by post-reform China (Huang et al., 2014). It can be associated with the reformation of state-owned enterprises from the mid-1990s, and marginalised groups including ethnic minorities, the homeless, disabled and aged people, who have been excluded from the rapidly growing and thriving labour markets (ibid.). It also can be related to households' second profession to increase their income as a part-time job, which frequently includes urban workers (if the main salary cannot support their family due to inflation or emergency) and peasants (rural migrants and non-busy farming seasons).

\subsubsection{The optimal and flexible features - preliminary functional actors}

Chinese street vendors often prefer locations with massive and stable pedestrian flows, which capitalise on spaces closely accessible to commuters and pedestrians (e.g. around underground stations, bus stations, schools, neighbourhoods and traffic nodes). They can precisely perceive different spatial properties in relation to their types of sale (i.e. fast foods, vegetables and fruits, small and cheap items, and living goods). For instance, typical street vendors selling vegetables generally emerge around high-density residential areas.

Street vendors are also able to perceive spatial-temporal features. They selling breakfast often appear in the morning peak. However, around the spaces of schools, the flexible business hours of street vendors seem precisely related to leisure time as well as the beginning and end of the school day. These street vendors will attract many children wishing to buy toys or snacks. From this point of linking to spaces, time could be seen as another narrative for specific walking behaviours, which relates the spatial-temporal features to the emergence of street vending. 


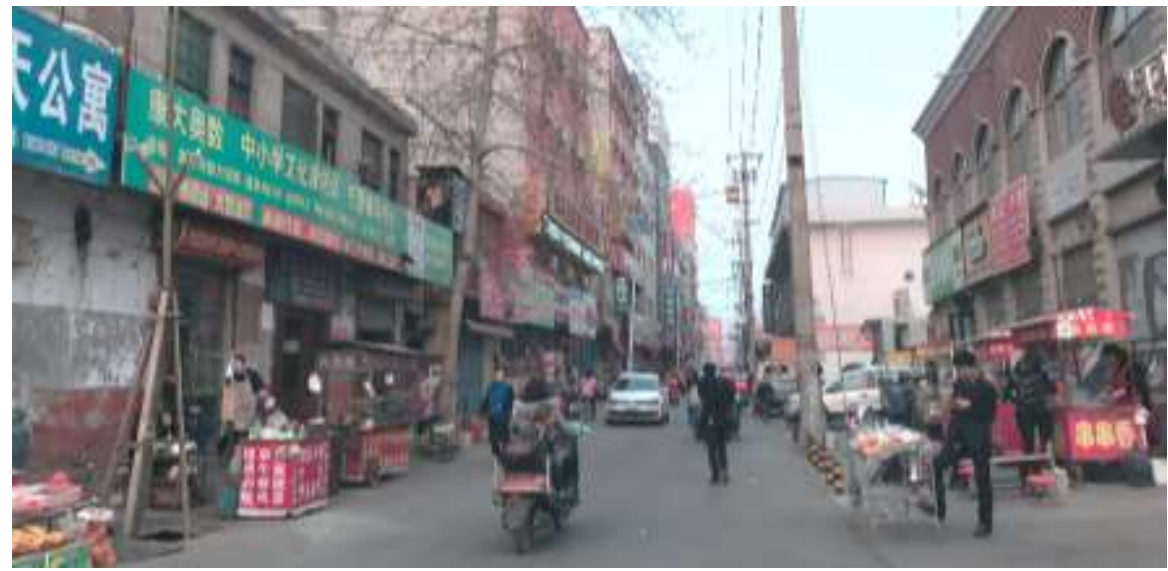

Figure 3: Street vendors selling snacks/toys emerged timely around an elementary school, Yuncheng

(Source: Ziwen Sun)

\subsubsection{A feature of walkable spaces - mobile actors}

The mixed-use strategy is one of the main methods to improve local walkability (Azmi \& Karim, 2013). The versatility and flexibility of street vending might be as a novel concept of 'mobile amenity', which can supplement surrounding facilities within a walkable distance, to satisfy the essential demands of everyday life for nearby residents. As such, street vendors seem to be an action possibility that can create a convenient walking environment, thereby bringing a series of additional benefits for nearby neighbourhoods from increased walkability (e.g. public health, neighbourhood harmony, interpersonal connections and safety). According to our observation, the majority of the relatively fixed street vendors' type is selling vegetables as semi-supplementing amenities. However, other vendors selling seasonal fruits is relatively mobile as transiently attractive amenities.

\subsection{Meanings of street vending - Immaterial actors of adaptability}

\subsubsection{The everyday life - a meaningful association between seller and buyer}

Street vending is complex since they have two different perspectives in the same space and time. One is to interpret the physiological needs of nearby residents in order to give people an urban micro-economic opportunity. The other is to understand the functions of street vendors from the nearby residents' perspective, as a service for everyday life. Simultaneously, the possibility of the association, both by seller and buyer, relates and increases the spatial value.

\subsubsection{A special association in Chinese cities - a kind of origin of street vendors}

Food is the most significant demand for human life, one of the most basic needs for everyone (Maslow et al., 1987). Dietary habit is often related to medical research. However, in this section, it will be represented in relation to spaces and demands. For instance, there are 
different dietary habits between the U.S. and China in daily life, especially the proportion of vegetables consumed (Kendall \& Pimentel, 1994; Volpe \& Okrent, 2012). Chinese everyday life much more depends on (leafy) vegetables than that of North Americans. Such (leafy) vegetables might be linked to fat-free in health but also about how many days the vegetables can be stored. Chinese people frequently buy (leafy) vegetables as that can only be freshly saved for a couple of days. This common dietary habit relates to Chinese people not wanting to spend one or two hours every few days going shopping to a far away supermarket. As a result, this collective dietary habit as an actor has shaped the unique Chinese phenomenon and spatial performance, which has resulted in every Chinese high-density residential area having vegetable sellers within a walkable distance.

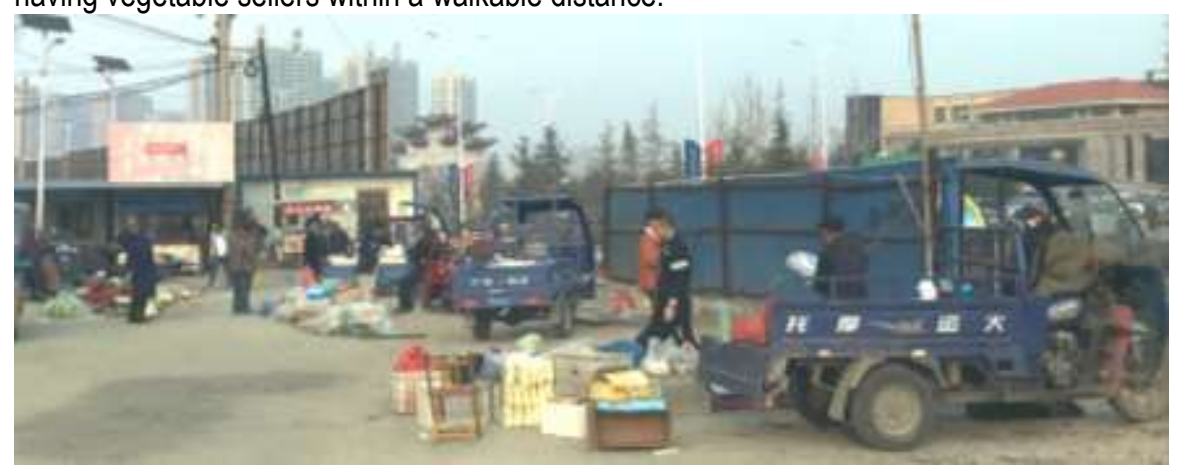

Figure 4: Street vendors selling vegetables emerged around high-density residential areas, Yuncheng (Source: Ziwen Sun)

\subsubsection{A meaningful association in the society and economy system}

The habit relates both a desire and need from residents, and this desire and need relate an opportunity of a frequent and basic urban micro-economy. It then relates an action possibility for low-income groups who can undertake street vending (e.g. selling vegetables). At the same time, the appearance of street vendors relates one of the mixed-use functions, increasing local walkability. Localised walkability, in turn, relates other types of street vendors regarding impulse buying in the same space. Various types of street vendors, in a shared place, produce a mutual economic system to assist each other, which induce multiple buyers (i.e. pedestrians). The entire system of street vendors relates a meaning of elastically collective benefits.

In the socio-economic domain, social progress is characterised by relationships of reciprocity. Petcou \& Petrescu (2015) convey that sharing spaces and infrastructures will reinforce these relationships. The system of assembled street vendors is a bottom-up framework to generate a self-organised system through self-employment, diversity, and microforms. Therefore, a set of street vendors might generate a collective participation to afford solidarity in relationships. The relationships of reciprocity are also involved with nearby residents. According to our observation, a strongly mutual trust and a close relationship have been built between relatively fixed street vendors (who frequently sell same goods in one place such as vegetables) and nearby residents (who regularly buy the goods). The highly 
resilient system from multiple features relates the meaning of incomparable adaptability so that the phenomenon of street vendors can be timeless and placeless, which reproduces the specific walkable space.

\subsection{Results \& Discussion}

People react and act not only to space itself but also the story and meaning behind it. Using ANT is an alternative way to analyse the actors and associations of street vendors, which is the reason why the street vendors have highly resilient features and how they can contribute to walkability. The overarching thesis of this paper demonstrates an irreducible heterogeneous network of street vendors as a paradigm of walkability.

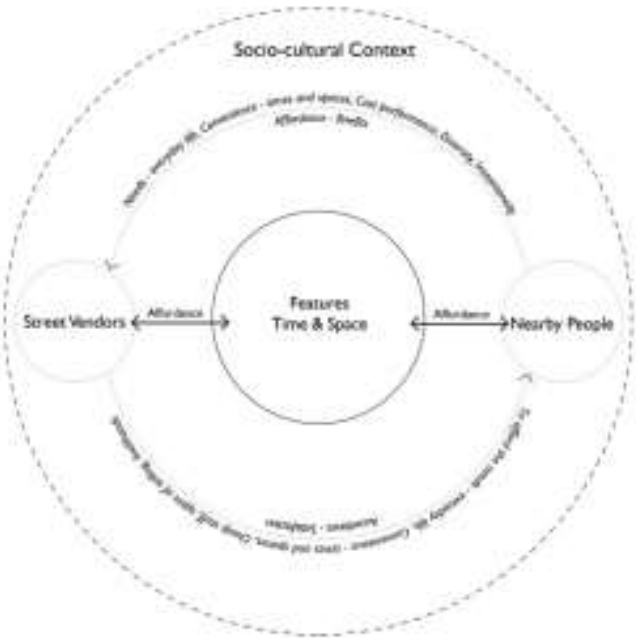

Figure 5: The diagram illustrates an actor-network of street vending as a paradigm of walkability (Source: Ziwen Sun)

People belong to different groups that intertwine to set an interactional network under the same socio-cultural context. The different groups have different communal properties that interweave and reflect in different time and spaces. In the Chinese context, the group of street vendors represents the main property of survival and livelihood. The needs of everyday life for nearby people offer the micro-economy and match to the communal property of street vendors. The street vendors can satisfy the needs with less investment. Furthermore, the different groups understand different spatial-temporal properties, as well as features of other groups. For example, in the same space, the nearby people might see the property as "dirty and crowded but cheap and convenient". However, the street vendors might consider the property is "time for more walking and staying, needs and micro-economy."

This research is a novel study, which might alter researchers' conventional perspectives on Chinese street vendors. Namely, street vendors are not "issues" and do not "need to be 
solved". In other words, we have to understand the network and configuration of street vendors regarding the multiple meanings of a specific walkable space, instead of a result. This study might have some biases because the analysis of materials is based on the researchers' judgement and the materials are selected by the researchers. Furthermore, if any actor is removed or added to this actor-network, the network configuration might change due to the equilibrium would have to be maintained.

\subsection{Conclusion}

Using ANT as a conceptual tool, this study has shown additional knowledge to why walkability, and how a specific walkable space is configured in the Chinese context. It traced how patterns of everyday life fundamentally influenced the actor-network of street vending in relation to a paradigm of walkability. In Yuncheng, street vendors exist, in part, as a coping mechanism in order to deal with the demands of the surroundings and livelihoods. We also consider 'street vending' not as a 'thing', but rather as a broader set of ideas and actions, based on multiple shifting relations and entrenched associations. We suspect other Chinese cities might have similar situations that shape the actor-network of street vending, which could be further used to study the specificity of walkability. The objective of this paper has been to propose a heterogeneous hypothesis and positive possibilities, which lead to breaking away from the conventional studies of street vendors. Namely, the multi-threading processes of street vending offer a heterogeneous network to understand the specific walkable spaces in contemporary Chinese cities

\section{Acknowledgements}

We would like to express our sincere gratitude to OPENspace Research Centre, Edinburgh School of Architecture and Landscape Architecture, Edinburgh College of Art, University of Edinburgh. We also give our sincere gratitude to the financial support from the programme of China Scholarship Council (No.201608060149).

\section{References}

Brookfield, K., Ward Thompson, C., \& Scott, I. (2017). The uncommon impact of common environmental details on walking in older adults. International Journal of Environmental Research and Public Health, 14(2). DOI: 10.3390/ijerph14020190

Castells, M. (1996). The Rise of the Network Society, The Information Age: Economy, Society and Culture. Oxford: Blackwell Publishers.

Ewing, R., \& Handy, S. (2009). Measuring the Unmeasurable: Urban Design Qualities Related to Walkability. Journal of Urban Design, 14(1), 65-84.

Huang, G., Xue, D., \& Li, Z. (2014). From Revanchism to Ambivalence: The Changing Politics of Street Vending in Guangzhou. ANTI Antipode, 46(1), 170-189. 
Moore, J. A. (2015). "Why Ancient Cities Can Still Teach Us About Urban Planning" 25 Aug 2015. ArchDaily. Available from http://www.archdaily.com/772464/why-ancient-cities-can-still-teach-us-about- urban-planning

Kelly, K. (2010). What technology wants. New York: Viking.

Kendall, H.W., \& Pimentel, D. (1994). Constraints on the Expansion of the Global Food Supply. AMBIO STOCKHOLM-, 23(3), 198.

Latour, B. (1987). Science in Action: How to Follow Scientists and Engineers Through Society, Harvard University Press, Cambridge, MA.

Latour, B. (2005). Reassembling the Social: An Introduction to Actor-Network Theory. Clarendon: Oxford University Press.

Le, C., \& Etchells, F. (1946). Towards a new architecture. London: Architectural Press.

Liu, K. (2013). Street vendors in Chinese cities since economic reform : a case study of Guangzhou. Available from http://worldcat.org/z-wcorg/database.

Maslow, A. H., Salenger Educational, M., \& Shooting Star, P. (1987). Maslow's hierarchy of needs. Santa Monica, CA: Salenger.

Mitev, N. (2009). "In and out of actor-network theory: a necessary but insufficient journey", Information Technology \& People, 22 (1), 9-25.

Murray, J. K. (1997). Water Under a Bridge: Further Thoughts on the "Qingming" Scroll. jsongyuanstud Journal of Song-Yuan Studies, (27), 99-107.

Norberg-Schulz, C. (1980). Genius loci: towards a phenomenology of architecture. New York: Rizzoli

Pentland, B. T. and Feldman, M. S. (2007). "Narrative networks: patterns of technology and organization", Organization Science, 18 (5), 781-795.

Petcou, C., \& Petrescu, D. (2015). R-URBAN or how to co-produce a resilient city, ephemera theory \& politics in organization, 15(1), 249-262.

Ramiller, N. C. \& Wagner, E. L. (2009), "The element of surprise: appreciating the unexpected in (and through) actor networks", Information Technology \& People, 22 (1), 36-50.

Sheehan, R., \& Vadjunec, J. M. (2012). Placing community through actor-network theory in Oklahoma's 'No Man's Land'. Soc. Cult. Geogr. Social and Cultural Geography, 13(8), 915-936.

Saelens, B. E., Sallis, J. F., \& Frank, L. D. (2003). Environmental correlates of walking and cycling: Findings from the transportation, urban design, and planning literatures. Annals of Behavioral Medicine, 25(2), 80-91.

Saelens, B., \& Handy, S. (2008). Built Environment Correlates of Walking: A Review. Medicine and Science in Sports and Exercise, 40 (7), S550

Speck, J. (2013). Walkable city how downtown can save American, one step at a time. New York: North Point Press.

Sun, Z., \& Kong, W. (2015). Learning public life from Gangxia, Book Chapter, Published by Retumu Urban Rural Institute, p.40-73 
Sun, Z., et.al. / Asian Journal of Behavioural Studies (AjBeS), 3(13) Sep / Oct 2018 (p. 190-200)

Sun, Z., Liu, C., \& Kong, W. (2015). The Study of Walk Score and its Enlightenment in China: Based on the International Research Development, Conference Proceedings, Published by Chinese Annual National Planning Conference, TU984

Vayda, A. P. (1983). Progressive contextualization: methods for research in human ecology, Human Ecology, 3 : 265-281.

Volpe, R., \& Okrent, A. (2012). Assessing the healthfulness of consumers' grocery purchases. from http://purl.fdlp.gov/GPO/gpo46307

Wissink, B. (2013). Enclave urbanism in Mumbai: An Actor-Network-Theory analysis of urban (dis)connection. Geoforum, 47(51), 1-11. 